\title{
Protector effect of beta-glucans from shrimp pond-related yeasts in Penaeus vannamei rearing under white spot syndrome virus presence
}

\author{
Norma A. Ochoa-Álvarez ${ }^{1,2}$, Ramón Casillas-Hernández ${ }^{1}$, Francisco J. Magallón-Barajas² \\ Jesús M. Ramirez-Orozco ${ }^{2}$ \& Elizabeth Carvajal-Millan ${ }^{3}$ \\ ${ }^{1}$ Instituto Tecnológico de Sonora, Departamento de Ciencias Agronómicas y Veterinarias \\ Área de Acuicultura, Obregón, Sonora, México \\ ${ }^{2}$ Centro de Investigaciones Biológicas del Noroeste, La Paz, BCS, México \\ ${ }^{3}$ Centro de Investigación en Alimentación y Desarrollo, Biopolímeros, Hermosillo, Sonora, México \\ Corresponding author: Norma Ochoa-Álvarez (nochoa04@ cibnor.mx)
}

\begin{abstract}
This research study tested the protective effect of prolonged exposure of shrimp food supplemented with glucans from shrimp-pond related yeasts on shrimp Penaeus vannamei reared under the presence of the white spot syndrome virus (WSSV). The glucans extracted and purified from isolated marine yeasts identified as Debaryomyces hansenii, Candida tropicalis, Candida humilis, Candida glabrata, Pichia kudriavzevyi, Wickerhamomyces anomalus and the terrestrial Saccharomyces cerevisiae yeast were characterized by the Fourier-transform infrared spectroscopy and proton nuclear magnetic resonance spectroscopy. The treatments were prepared with food enriched with the yeast beta-glucans and the control groups without beta-glucans. Shrimp were fed thrice a day and challenged orally with WSSV on days 31, 54, 66 and muscularly at day 70. The animals were assessed for the protective effect in terms of post-infection total hemocyte counts, and survival rate. The results indicated that marine yeasts possessed $\beta-1,3 / 1,6$-glucans, and that $D$. hansenii was an excellent source yielding $30 \%$ of its dry biomass of pure glucans. For the positive control group where no glucans were added, WSSV challenges showed $100 \%$ survival when the virus was provided orally, and $40 \%$ when the virus was injected. These results also indicated that the shrimp line selected for this study was a resistant line for WSSV. Shrimp groups fed with glucans of the marine yeasts $D$. hansenii and $C$. humillis showed a significant protection, allowing shrimp survival of $66 \%$ while terrestrial yeast showed $57.14 \%$. These results indicated that marine yeasts growing in the shrimp pond were an excellent source of betaglucans that allowed extra protection against the mortality caused by this pathogenic virus.
\end{abstract}

Keywords: Penaeus vannamei; shrimp; WSSV; yeast; beta-glucan; rearing; aquaculture

\section{INTRODUCTION}

The shrimp industry is one of the fastest-growing activities worldwide, both in the economic environment and its contribution to human nutrition (Castillo-Juárez et al. 2015), of which the white shrimp Penaeus vannamei is one of the most farmed and exploited species (Gong et al. 2012). However, this activity is not free of environmental and disease problems, mainly caused by pathogenic microorganisms (Perez-Enriquez et al. 2018, Flegel 2019). One of these diseases is the white spot syndrome virus (WSSV), which is not only important due to the high mortality rates but also for its capacity to infect a large number of crustaceans, leading to significant ecological risk (Witteveldt et al. 2004, Sarlin \& Philip 2011, Parrilla-Taylor 2018).

One of the strategies to reverse WSSV infections has been to improve shrimp lines through the genetic selection to obtain resistance to viral infections and other diseases (Perez-Enriquez et al. 2009, Mohan et al. 2018) besides considering the nutritional factor as a source of additional protection. In the last strategy, countless efforts have been made to provide shrimp with the necessary elements to achieve optimal development and growth during the crop cycles and improve its resistance to various diseases. For example, adding molecules to shrimp feed to stimulate their defense system, such as glucans, have been used to con-

Corresponding editor: Alvaro Bicudo 
trol some viral or bacterial diseases in crops, reducing mortalities and providing protection against resistant pathogens to drugs (Sajeevan et al. 2009, Bai et al. 2014).

Glucans are part of a group of compounds known as "biological response modifiers" and found in the cell wall of yeasts, fungi, and seaweeds (Uriza-Pinzón 2014, Vetvicka \& Vetvickova 2016). Glucans interact with several receptors in microorganisms, invertebrates, and mammals, initiating several immune responses (Legentill et al. 2015). Research studies have reported the use of glucans obtained from yeasts, both of terrestrial and marine origin, indicating they are excellent sources for beta-glucans that confer protection against pathogenic microorganisms in Penaeid shrimp (Sukumaran et al. 2010, Flores-Miranda et al. 2011, Deng et al. 2013, Subramanian \& Philip 2013, Bai et al. 2014). However, not all beta-glucans possess immunostimulatory properties; moreover, they vary depending on the source and even within the same source (Stier et al. 2014, Wang et al. 2016).

Additionally, yeast beta-glucans' leading source is the model yeast Saccharomyces cerevisiae, but very few studies have been performed in non-conventional yeasts, even less, with microorganisms coinhabiting with shrimp. Therefore, this study evaluated the prolonged exposure of beta-glucans extracted from yeasts associated with shrimp farming to determine their protective effect on shrimp rearing challenged with WSSV.

\section{MATERIALS AND METHODS}

\section{Yeast isolation}

The marine yeasts used in this study were obtained by microbiological isolation of water and bottom samples obtained from Penaeus vannamei ponds at Mahr Aquaculture Farm (Pichilingue, Baja California Sur, México). Yeast strains were obtained by sequential streaking on the Petri dish until pure colonies were obtained. Strains were preserved at $4^{\circ} \mathrm{C}$ on yeast-media plus antibiotics for short term use or at $-80^{\circ} \mathrm{C}$ with glycerol as a cryogenic preservative for long term use. As a reference, terrestrial Saccharomyces cerevisiae strain was obtained as described from $S$. cerevisiae powder (Marcq-en-Baroeul, FR).

\section{Yeast identification}

Identification was performed as described by Kurtzman \& Robnett (1998) with some changes. Briefly, DNA was extracted using the Fast DNA Spin Kit for Soil, following the manufacturer's instructions (MP Biomedicals, Santa Ana, CA, USA). DNA quality and purity were assessed by agarose gels using GelRed and a photo documenter (BioDoc-IT UVP, Upland, CA, USA). DNA quantity was determined by NanoDrop determination (Thermo Scientific, Willmington, DE, USA). Primers used were NL-1 for forwarding string (5'-GCATATCAATAAGCGGAGGAAAAG) and NL-4 for reverse string (5'-GGTCCGTGTTTCAAGACGG), which amplified a variable region of the D1/D2 domains of the large ribosomal DNA (26s rDNA) subunit. DNA amplification was performed in a thermocycler (Verity Applied Biosystems, CA, USA) using the following thermal cycling program: one cycle at $95^{\circ} \mathrm{C}$ for one min; followed by 35 cycles at $94^{\circ} \mathrm{C}$ for $60 \mathrm{~s}$, at $55^{\circ} \mathrm{C}$ for $60 \mathrm{~s}$, and at $72^{\circ} \mathrm{C}$ for $30 \mathrm{~s}$; one cycle $72^{\circ} \mathrm{C}$ for $7 \mathrm{~min}$ and a final step at $4^{\circ} \mathrm{C}$ for $10 \mathrm{~min}$. Agarose gels and quantity assessed quality by NanoDrop determination. The obtained amplicons from polymerase chain reaction (PCR) were purified and sequenced by the MacroGen Company in Seoul, Korea. The obtained chromatograms were visually corrected using the BioEdit program (https://bioedit. software.informer.com). Consensus sequences were obtained using the ClustalW program. The nucleotides were resolved by visual inspection, genera, and species by sequence comparison with the National Center for Biotechnology Information (NCBI, USA) nucleotide data bank. The identification results were corroborated using a specialized yeast platform, named YeastIP (The International Center of Microbial Resources, French National Agronomical Research Institute, France).

\section{Biomass production}

The marine yeast biomass was prepared using yeastpeptone-dextrose (YPD)-broth medium (DIFCO, Detroit, MI, USA) and maltha-broth for terrestrial yeast. Erlenmeyer flasks with yeast cultures were incubated at $30^{\circ} \mathrm{C}$ and $100 \mathrm{rpm}$ for $24 \mathrm{~h}$. Biomass was recovered by centrifugation at $5000 \mathrm{~g}$ per $15 \mathrm{~min}$ at $4^{\circ} \mathrm{C}$ (Megafuge 16R, Thermo Scientific, Waltham, MA, USA) and dried to obtain lyophilized powder (Labconco Freeze Dryer, Kansas City, MO, USA).

\section{Beta-glucan extraction}

Glucans were extracted from lyophilized biomass following Williams et al. (1991) with some modifications. Two grams of yeast biomass was resuspended in $40 \mathrm{~mL}$ of $3 \% \mathrm{NaOH}$ solution and boiled for three $\mathrm{h}$ at $90^{\circ} \mathrm{C}$. Samples were centrifuged at 5000 g per $30 \mathrm{~min}$ at $4^{\circ} \mathrm{C}$. The precipitate was collected and treated thrice as described for the biomass. Fifteen milliliter of $0.5 \mathrm{~N}$ acetic acid was added to the precipitate and boiled at $75^{\circ} \mathrm{C}$ for $6 \mathrm{~h}$. The suspension was centrifuged at $5000 \mathrm{~g}$ per $30 \mathrm{~min}$ at $4^{\circ} \mathrm{C}$ and resuspended in $15 \mathrm{~mL}$ of ethanol at boiling temperature. 
The suspension was centrifuged as previously performed, and the precipitate recovered. Steps from acetic acid to ethanol boiled addition were repeated thrice. Finally, the precipitate was washed with distilled water and centrifuged each time, as described before. The recovered pellet was lyophilized using the FreezerDryer described before and preserved at room temperature until use.

\section{Chemical characterization of extracted glucans}

The obtained glucans were analyzed for $\beta-1,3 / 1,6$ bond presence, glycogen content, Infra-Red Spectra, and Proton nuclear magnetic resonance (NMR) Spectrum. The glycogen determination was performed quantifying glucose through high-performance liquid chromatography (HPLC) (Waters Alliance e2695, Milford, MA, USA) after enzymatical hydrolysis with amylase/amyloglucosidase (Sigma-Aldrich). The determination of $\beta-1,3 / 1,6$ bonds was performed through Congo Red Dye (Nitschke et al. 2011). The infrared spectrum was obtained in the Nicolet Fouriertransform infrared (FTIR) spectroscopy iS50 FT-IR (Waltham, MA, USA), with total attenuated reflection (ATR) by Fourier-transform infrared (ATR-FTIR) spectroscopy in a spectrum range from $400-4000 \mathrm{~cm}^{-1}$. The proton nuclear magnetic resonance $(\mathrm{NMR}+\mathrm{H})$ spectrum was analyzed by dissolving $8 \mathrm{mg}$ of sample in deuterated dimethyl sulfoxide in a Bruker Advance $600 \mathrm{Mhz}, \mathrm{BBOF}$ probe (Billerica, MA, USA)

\section{Shrimp feed production}

Food was prepared at Centro de Investigaciones Biológicas del Noroeste (CIBNOR) food plant as follows. The formulation was carried out with the Nutrion ${ }^{\circledR}$ program (Guadalajara, México). Table 1 summarizes the nutrients added to prepare the basal shrimp feed for the control groups. This basal diet was added with the different purified glucans at a $0.2 \%$ proportion for the challenge experiments. Nine treatments were prepared, containing $27.52 \%$ crude protein and $7.03 \%$ lipids, of which seven treatments were supplemented with yeast beta-glucans. The other two treatments were used as control groups, one negative with no yeast beta-glucans and not virus, and the other positive treatment with WSSV but no betaglucans. Before preparing the experimental feed, the macro ingredients: fishmeal, soybean-paste, and wheatflour were ground and sieved through a $250 \mu \mathrm{m}$ mesh sieve. The dry ingredients were thoroughly mixed in a food mixer, and oil fish and soybean were added. Pellets were produced through a meat mill using a $2 \mathrm{~mm}$ sieve. The produced pellets were dried in a convection oven at $60^{\circ} \mathrm{C}$ to obtain humidity from 8 to $10 \%$.
Table 1. Composition of experimental feeds.

\begin{tabular}{lrc}
\hline Ingredients & $\begin{array}{c}\text { Control feed } \\
(\%)\end{array}$ & $\begin{array}{c}\text { Experimental } \\
\text { glucan feed }(\%)\end{array}$ \\
\hline Fish meal & 6.5 & 6.5 \\
Soybean paste & 30.8 & 30.8 \\
Wheat flour & 48.4 & 48.4 \\
Fish oil & 4.1 & 3.9 \\
Soy lecithin & 2.2 & 2.2 \\
Alginic acid & 2.0 & 2.0 \\
Tryptophan & 0.2 & 0.2 \\
Methionine & 0.1 & 0.1 \\
Arginine & 0.1 & 0.1 \\
Vitamin and & 5.6 & 5.6 \\
mineral mixture & & \\
Glucan yeast & 0 & 0.2 \\
\hline
\end{tabular}

\section{Inclusion of glucans in the feed}

Glucans were mixed with fish oil (41.1 $\mathrm{g}_{\text {oil }} \mathrm{kg}^{-1}$ feed) and added to the dried pellets using a sprinkler. The final beta-glucans concentration was $0.2 \%$ of the feed. A different preparation was made for each of the betaglucans of the assayed yeasts. As previously mentioned, the control groups were prepared without beta-glucans.

\section{Animal management}

The authors confirm that this study adhered to ethical policies. Animal ethics approval was not required for crustacean species, but it was conducted following standard practices.

\section{Bioassays design}

The shrimp used in this study were acclimatized in the Aquaculture Laboratory of the Instituto Tecnológico de Sonora (ITSON, Ciudad Obregón, SON, MX), as follows. Thirty juvenile of $P$. vannamei shrimp weighing $2 \pm 0.67 \mathrm{~g}$ were selected. The absence of WSSV was determined by polymerase chain reaction (PCR) analysis. Shrimp were placed in acclimation units (200 L aquariums filled with $150 \mathrm{~L}$ water) with aerated water at room temperature and weekly $33-50 \%$ water exchange (no recirculating aquaculture system was used). Organisms were fed thrice a day for 25 days, using an average from $8-12 \%$ of feed relative to the organisms' weight. For the experimental units, eight shrimp were selected and placed in $40 \mathrm{~L}$ aquarium on day 26 and maintained under the same conditions as before. In total, 27 experimental units were used. Organisms were fed each day with the feed-BG preparation. Bioassays were developed by triplicate (three aquaria per assay). Eight organisms weighing 5.2 $\pm 1.0 \mathrm{~g}$ were confined to each aquarium. Three challenges were performed orally by feeding $1 \mathrm{~g}$ of WSSV shrimp-infected tissue per aquarium on days 31 , 
54, and 66. WSSV was determined by PCR using the IQ Real Kit (GeneReach Biotechnology Corp, Taiwan) with no quantification. Because the shrimp line turned out to be WSSV resistant, a fourth challenge was performed on day 70 by injecting shrimp $20 \mu \mathrm{L}$ of a WSSV suspension per gram of shrimp weight with a 1 $\mathrm{mL}$ insulin syringe. The experiment was monitored for $120 \mathrm{~h}$. Survival rates were recorded every $12 \mathrm{~h}$.

\section{Hemolymph collection and total hemocyte count (THC)}

On day three post-infection intramuscularly, four shrimp individuals were randomly selected from each treatment for THC determination. Shrimp hemolymph $(100 \mu \mathrm{L})$ was collected with an insulin syringe prefilled with $200 \mu \mathrm{L}$ of EDTA-citrate anticoagulant (100 $\mathrm{mM}$ glucose, $30 \mathrm{mM}$ sodium citrate, $510 \mathrm{mM} \mathrm{NaCl}$, and $10 \mathrm{mM}$ EDTA). Formaldehyde was added $(400 \mu \mathrm{L})$ for fixing hemocytes to measure THC in a Neubauer chamber.

\section{Statistical analysis}

One-way ANOVA determined the statistically significant difference between experimental feeding groups; differences in multiple comparisons among group means were determined using Tukey's test $(P<0.05)$.

\section{RESULTS}

\section{Marine yeast isolation}

A total of 21 strains of culturable marine yeasts were isolated from the shrimp ponds. The analyses of the D1/D2 domains of the 26s rDNA determined that the isolated yeasts corresponded to only seven species, which belonged to four different genera. Table 2 summarizes the different genera and species isolated, all of which were used to generate yeast biomass for glucan extraction.

\section{Beta-glucans extraction}

The alkali-acid method allowed obtaining an extract consisting of glucan and glycogen, which was insoluble in water. With glycogen and glucans, the extract also had minimal cellular debris quantities, which were not considered for calculation. The amount and concentration of the extracted beta-glucans were obtained once the amount of glycogen was determined. The amount of glucan-glycogen obtained was variable and speciesdependent, whose values ranged from 2.5 to $43.54 \%$ of the used biomass dry weight, which revealed that the maximum glucan extraction percentages were for the marine yeast Debaryomyces hansenii (Table 2).

Regarding the glucan-glycogen ratio in the obtained extract, on average, the relationship for the marine yeast was determined to be 64.16-35.84\% (respectively), corresponding to the yeasts $D$. hansenii and Candida glabrata (70\%) the highest glucan value and the lowest one (52\%) for the yeast Wickerhamomyces anomalus. In comparison with the terrestrial yeast Saccharomyces cerevisiae $(60 \%)$, the marine yeasts had better glucan content in the obtained extract (Table 2).

Glucan yield was calculated from the number of glucans obtained against the lyophilized yeast biomass used for the extraction. The results are summarized in Table 2, showing that the maximum glucan yield corresponded to the marine yeast $D$. hansenii (0.3), while the lowest one was for $W$. anomalus (0.013). As previously mentioned, the terrestrial yeast $S$. cerevisiae showed a low glucan yield value (0.0633).

\section{Glucan chemical characterization \\ Fourier-transform infrared (FTIR) spectroscopy}

The infrared spectra obtained using the FTIR technique represented patterns unique for each molecule type, which turned out to be very useful for determining some characteristics of unknown samples. The purity of the glucans extracted by the alkali-acid chemical extraction method allowed obtaining spectra in which characteristic bands could be observed for all the analyzed samples (Fig. 1). Bands from the 850-1350 region were characteristic to polysaccharides; bands at the 892 region corresponded to $\beta-1,3$ bonds; and those at 998 regions to $\beta-1,6$ bonds; at 3,300 the hydroxyl group band was detected. In general, bands in region 1400 corresponded to beta-glucans.

\section{Proton nuclear magnetic resonance (NMR) spec- troscopy}

Figure 2 shows the proton magnetic spectra obtained for the beta-glucans of the tested yeasts. They had very similar spectroscopic behavior because of the same number and type of peaks throughout the spectrum. The anomeric region could be seen from 4.3-4.6 ppm (anomeric proton). The spectrum from 4.7-4.8 ppm was characteristic for $\beta-1,3$ bonds and for branched linkages bonds $\beta-1,6$ were observed in the region from 4.4-4.5 ppm, which was characteristic of this type of bond. These results mean that the beta-glucans extracted from all the tested yeasts were linear $\beta-1,3$ glucans with branches at position $\beta-1,6$.

\section{Survival challenge}

Figure 3 shows that when the organisms were challenged with WSSV through an oral application, no adverse effects were found (day 31) even for the shrimp in the control group fed with the basal diet (non-glucan diet). A second (day 54) and third (day 66) applications 
Table 2. Characteristics of beta-glucans isolated from marine and terrestrial yeast. Amount and purity of beta-glucans obtained by the alkali-acid method. Values shown correspond to the average of three determinations.

\begin{tabular}{|c|c|c|c|c|c|c|}
\hline $\begin{array}{l}\text { Scientific name } \\
\text { (Strains) }\end{array}$ & $\begin{array}{c}\text { Dry weight } \\
\text { of biomass (mg) }\end{array}$ & $\begin{array}{c}\text { Extract } \\
\text { obtained (\%) }\end{array}$ & $\begin{array}{l}\text { Glycogen } \\
\text { content }(\%)\end{array}$ & $\begin{array}{c}\text { Glucan } \\
\text { content }(\%)\end{array}$ & $\begin{array}{c}\text { Glucans yield } \\
\text { (biomass/glucans) }\end{array}$ & $\begin{array}{c}\text { Link content } \\
\beta-1,3-1,6(\%)\end{array}$ \\
\hline Debaryomyces hansenii & 2000 & $\begin{array}{c}43.5 \\
(870 \mathrm{mg})\end{array}$ & $\begin{array}{c}30 \\
(261 \mathrm{mg})\end{array}$ & $\begin{array}{c}70 \\
(609 \mathrm{mg})\end{array}$ & 0.3045 & 79.35 \\
\hline Candida tropicalis & 2000 & $\begin{array}{c}24.5 \\
(490 \mathrm{mg})\end{array}$ & $\begin{array}{c}31 \\
(151.9 \mathrm{mg})\end{array}$ & $\begin{array}{c}69 \\
(338.1 \mathrm{mg})\end{array}$ & 0.1690 & 74.57 \\
\hline Candida humilis & 2000 & $\begin{array}{c}9.25 \\
(185 \mathrm{mg})\end{array}$ & $\begin{array}{c}36 \\
(66.6 \mathrm{mg})\end{array}$ & $\begin{array}{c}64 \\
(118.4 \mathrm{mg})\end{array}$ & 0.0592 & 74.39 \\
\hline Candida glabrata & 2000 & $\begin{array}{c}5.3 \\
(106 \mathrm{mg})\end{array}$ & $\begin{array}{c}30 \\
(31.8 \mathrm{mg})\end{array}$ & $\begin{array}{c}70 \\
(74.2 \mathrm{mg})\end{array}$ & 0.0371 & 84.20 \\
\hline Picchia kudriavzevii & 2000 & $\begin{array}{c}7 \\
(140 \mathrm{mg})\end{array}$ & $\begin{array}{c}40 \\
(56 \mathrm{mg})\end{array}$ & $\begin{array}{c}60 \\
(84 \mathrm{mg})\end{array}$ & 0.0420 & 82.12 \\
\hline Wickerhamomyces anomalus & 2000 & $\begin{array}{c}2.5 \\
(50 \mathrm{mg})\end{array}$ & $\begin{array}{c}48 \\
(24 \mathrm{mg})\end{array}$ & $\begin{array}{c}52 \\
(26 \mathrm{mg})\end{array}$ & 0.0130 & 71.61 \\
\hline Saccharomyces cerevisiae & 2000 & $\begin{array}{c}10.55 \\
(211 \mathrm{mg})\end{array}$ & $\begin{array}{c}40 \\
(84.4 \mathrm{mg})\end{array}$ & $\begin{array}{c}60 \\
(126.6 \mathrm{mg})\end{array}$ & 0.0633 & 74.74 \\
\hline
\end{tabular}

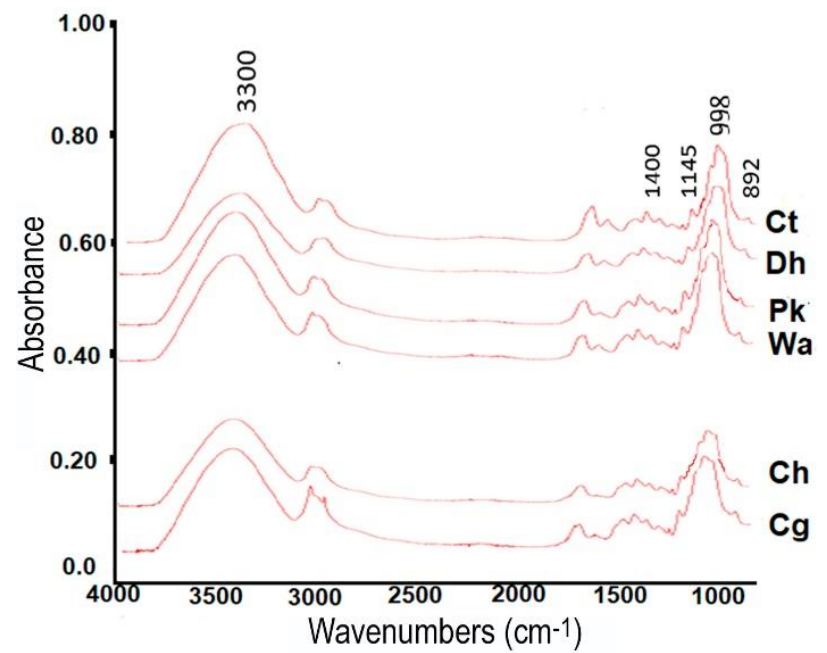

Figure 1. Fourier-transform infrared spectroscopy (FTIR). The spectrum of beta-glucans extracted from the cell wall of different yeasts by chemical methods. Pichia kudriavzevii (Pk), Wickerhamomyces anomalus (Wa), Candida tropicalis $(\mathrm{Ct})$, Debaryomyces hansenii $(\mathrm{Dh})$, Candida humilis $(\mathrm{Ch})$, Candida glabrata $(\mathrm{Cg})$.

of WSSV were necessary, obtaining similar results. At day 70, a WSSV application with a syringe was carried out to overcome the primary shrimp barrier, allowing the viral particles to be left directly in the shrimp tissue. Twelve hours after WSSV inoculation, the control (+) group, which was inoculated with WSSV but fed with no glucans, showed $50 \%$ of mortality, increasing to $60 \%$ at $24 \mathrm{~h}$ and remaining at this rate until the end of the experiment. Interestingly, the group fed with betaglucans from the marine yeast $C$. glabrata showed a greater mortality rate than the control group (+), and $W$. anomalus showed no significant difference. The shrimp group fed with the terrestrial yeast $S$. cerevisiae glucans had a $57.14 \%$ survival rate, which was greater than those shown by the marine yeasts $W$. anomalus, $C$. glabrata, C. tropicalis, and Pichia kudriavzevii but significantly lower than those for the marine yeasts $C$. humillis and D. hansenii.

\section{Total hemocyte count (THC)}

After the WSSV inoculum was applied intramuscularly, four shrimp were randomly selected from each treatment for THC determination at $72 \mathrm{~h}$. No statistical differences $(P<0.05)$ were found for THC for $W$. anomalus, and the negative control group (no WSSV inoculum and no glucans added). Groups with glucans from the marine yeasts $C$. tropicalis and $C$. humilis showed a statistical difference $(P<0.05)$ with respect to the negative and positive control group (WSSV inoculum and no glucans added). Marine yeasts $P$. kudriavzevii, D. hansenii, and terrestrial yeast $S$. cerevisiae showed greater THC counts than the positive control group, but no statistical differences $(P<0.05)$ was found (Fig. 4).

\section{DISCUSSION}

The attack of pathogenic microorganisms to shrimp ponds is one of the most pressing problems in the shrimp industry, of which the white spot virus is the main one. The use of immunostimulants that improve shrimp's ability to respond to external attacks has been proposed as an alternative, showing promising results. Beta-glucans are among the main proposed immunostimulants, and yeast beta-glucans have shown survival rates of up to $70 \%$ in the presence of WSSV (Wilson et 


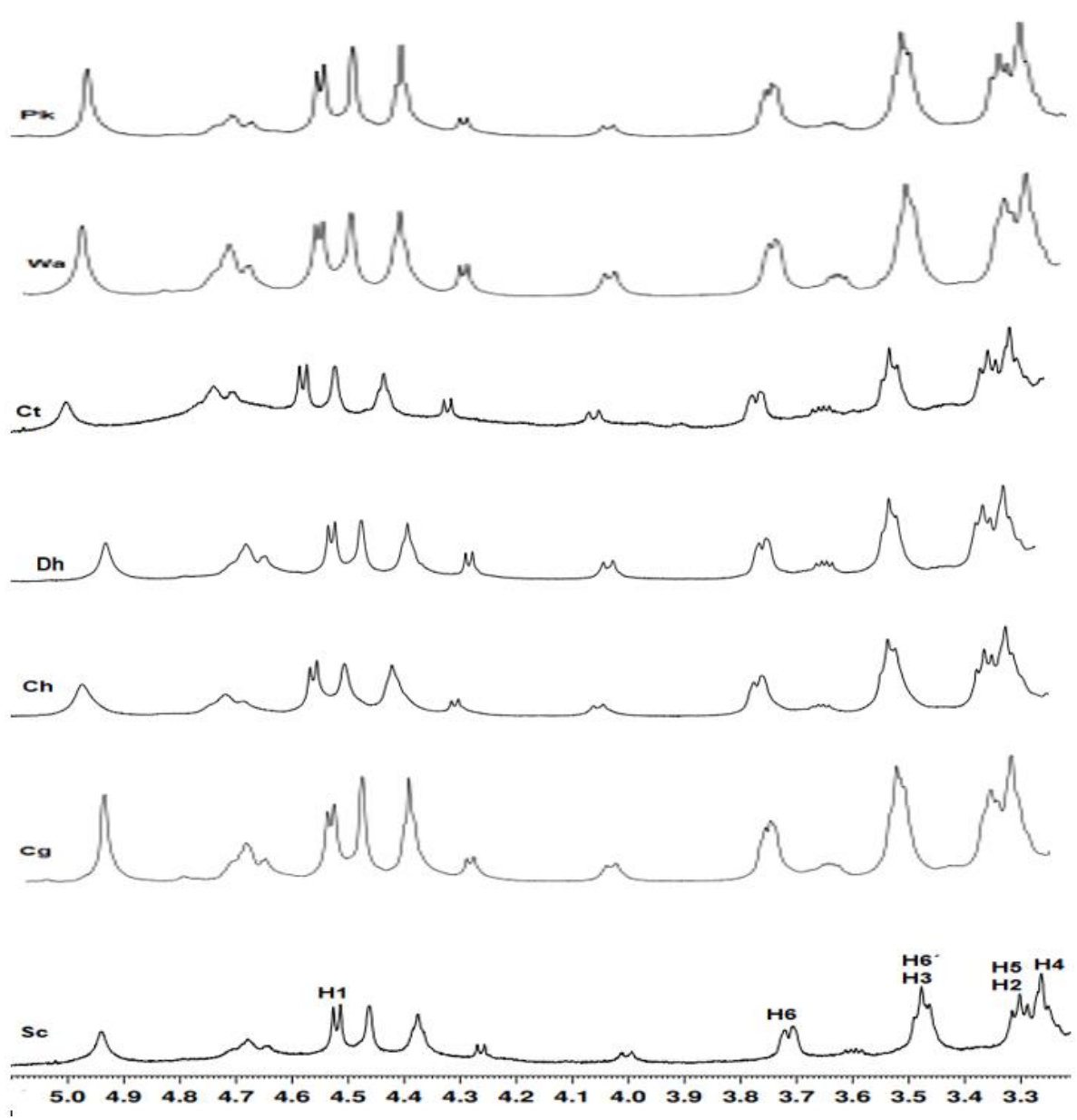

Figure 2. Proton nuclear magnetic resonance (NMR) spectrum of carbohydrate region of water-insoluble particulate betaglucan from six different marine yeasts isolates. Pichia kudriavzevii (Pk), Wickerhamomyces anomalus (Wa), Candida tropicalis (Ct), Debaryomyces hansenii (Dh), Candida humilis $(\mathrm{Ch})$, Candida glabrata $(\mathrm{Cg})$, and one terrestrial yeast Saccharomyces cerevisiae (Sc).

al. 2015). This study assessed the efficacy of prolonged exposure of marine yeast glucans associated with shrimp ponds for protecting shrimp in the presence of the WSSV virus. Surprisingly, the shrimp line selected for this study was found to be resistant to the WSSV. Moreover, some isolated marine yeasts' glucans showed a greater protector effect than glucans for the terrestrial yeast Saccharomyces cerevisiae. These findings indicated that some marine yeasts that grow jointly with Penaeus vannamei might be a good source for biological compounds; beta-glucans could confer a better protector effect than those obtained from terrestrial sources, improving the survival rate even to resistant shrimp to the WSSV virus.

Some studies have reported that yeast beta-glucans improved the growth of several organisms, including shrimp (Shurson 2017, Jin et al. 2018); however, no study has been performed to our knowledge to date beta-glucans of the microbiota associated with shrimp farming ponds have been evaluated. The marine yeast strains obtained from the shrimp pond were characterized by analyzing the D1/D2 region of the large ribosomal DNA subunit (Kurtzman \& Robnett 1998). These analyses allowed establishing the presence of four genera of culturable marine yeasts Pichia, Wickerhamomyces, Candida, and Debaryomyces coinhabiting the pond with P. vannamei. Although studies have already described marine yeasts from the genera Candida and Debaryomyces as potential sources for immunostimulants, either using the whole-cell, cell extract or its semi-purified or purified beta-glucans (Dalmo \& Bogwald 2008, Sukumaran et al. 2010, Flores-Miranda et al. 2011, Deng et al. 2013), in the same manner, beta-glucans from the marine yeasts Wickerhamomyces and Pichia have been analyzed for the first time in this study.

Several methods have been reported for betaglucans extraction (Ahmad et al. 2010, Sivamaruthi et al. 2016). Among those, chemical methods are the most used to extract glucans from cereals, yeasts, and 

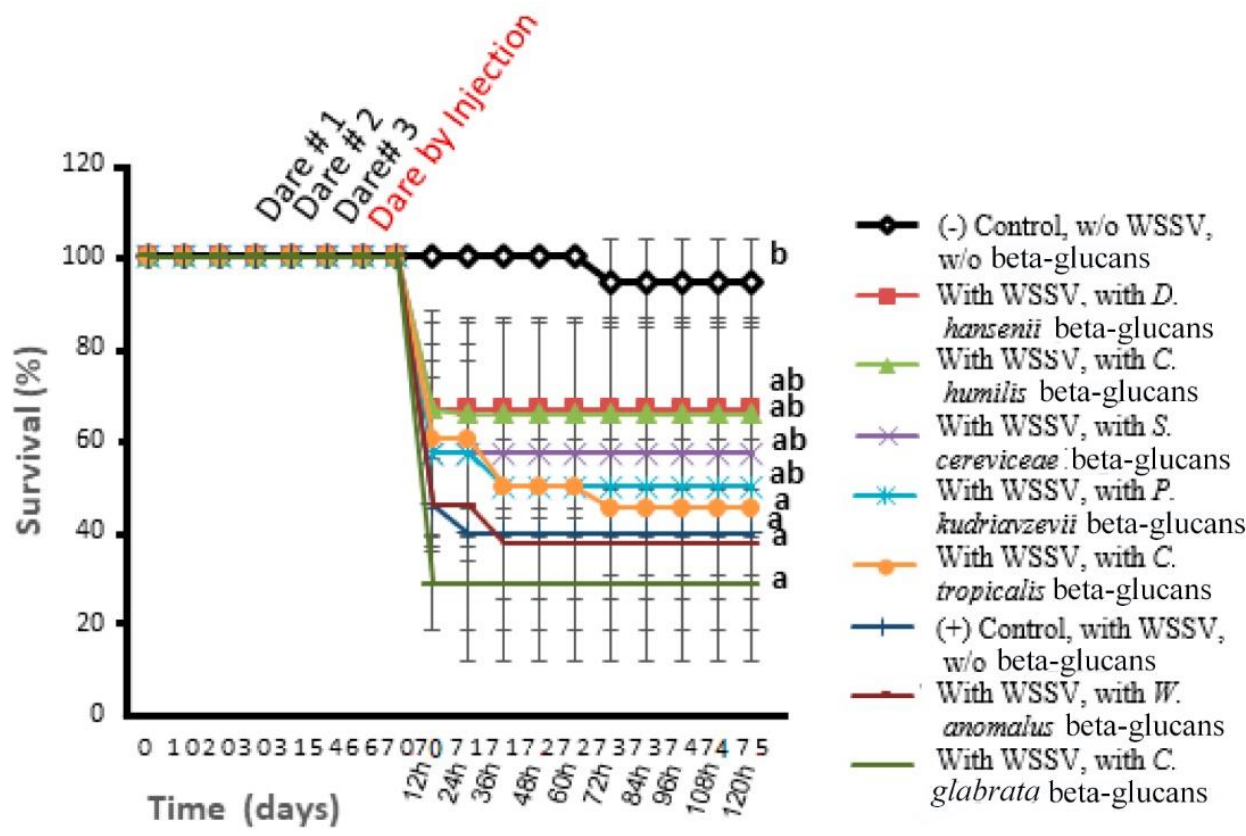

Figure 3. Post-challenge survival of Penaeus vannamei juveniles for 75 days fed with different marine yeast beta-glucans incorporated to diets and challenged with the white spot syndrome virus (WWSV). The line graphs with different letter were significantly different $(P<0.05)$.

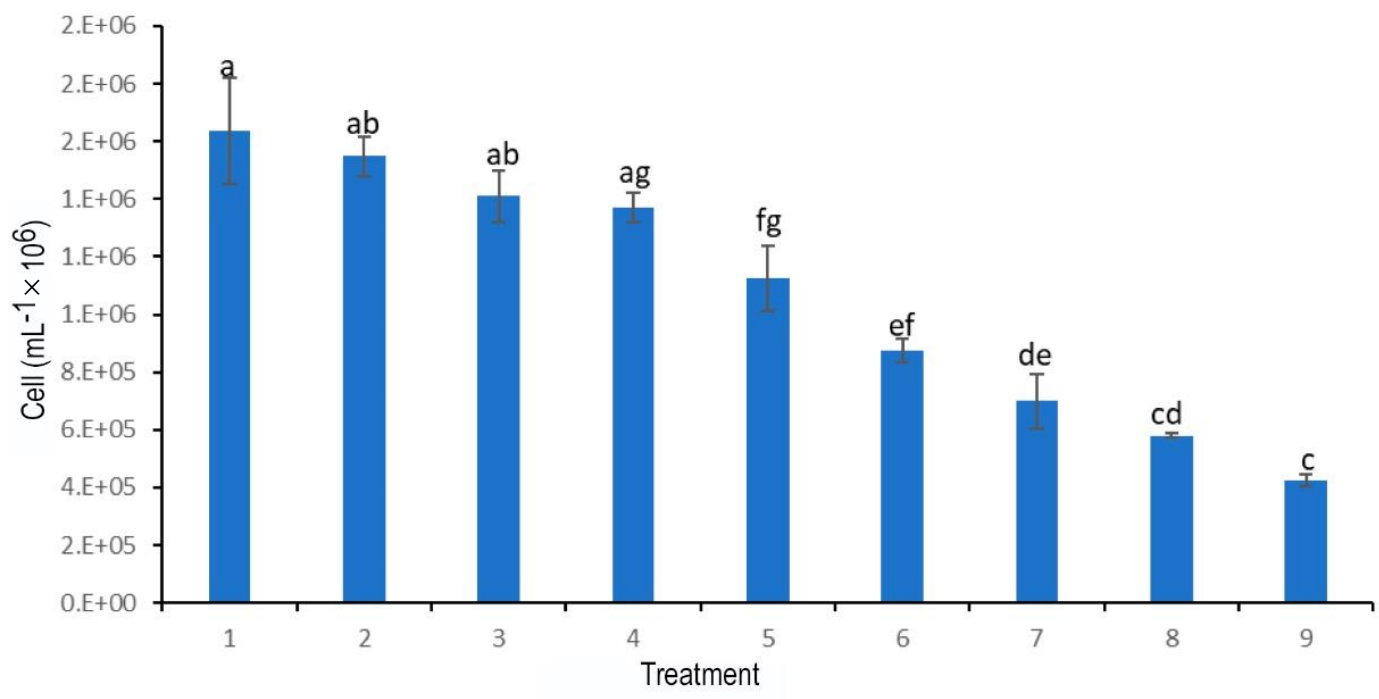

Figure 4. Total hemocyte count (THC). The number of hemocytes per milliliter of hemolymph in Penaeus vannamei shrimp groups fed with yeast beta-glucans, $72 \mathrm{~h}$ after white spot syndrome virus (WSSV) inoculum. 1) Pichia kudriavzevii glucans, 2) Saccharomyces cerevisiae glucans, 3) Debaryomyces hansenii glucans, 4) positive control group (with WSSV, without glucans), 5) Candida glabrata glucans, 6) Candida humilis glucans, 7) Candida tropicalis glucans, 8) Wickerhamomyces anomalus glucans, 9) negative control group (without WSSV, without BG). Different letters indicate significant differences $(P<0.05)$. Bars represented means with standard deviation $(\mathrm{n}=3)$.

microalgae (Volman, 2007), but every extraction method affects the structure, quality, and functionality of beta-glucans. Using chemical methods, Sukumaran et al. (2010) found that the marine yeast Debaryomyces hansenii contributed the most beta-glucans with a 0.124 yield, which agrees with our results where this yeast produced the highest quantity of glucans with a 0.3 yield. Wilson et al. (2015) reported that out of eight strains of the marine yeasts evaluated, D. fabryi was one with the highest glucan yield with 0.275 , while Angulo et al. (2018) reported a yield of 0.1482 for $D$. hansenii. In this study, the beta-glucans obtained from 
Wickerha-momyces anomalus and Candida glabrata had the lowest yields with values of 0.013 and 0.037 . In general, the yields obtained by the method here described were higher than those reported by the studies mentioned above, obtaining a 0.3 yield for the marine yeast $D$. hansenii, which showed the greatest amount of glucans extracted even in comparison with the terrestrial yeast $S$. cerevisiae.

The methods used to supply the beta-glucans to shrimp can be divided into direct or indirect methods. Direct methods are invasive, usually subcutaneous or intramuscular, and performed with a needle and syringe. In indirect application methods, beta-glucans are introduced to the shrimp by immersion, using a cannula, or by including them into shrimp feed (FloresMiranda et al. 2011, Fonseca-Moreno et al. 2013). All methods mentioned, except for the latter, have the disadvantage of requiring direct handling of organisms, and thus less attractive for their use by the industry. Initially, due to the low systemic availability of oral preparations, beta-glucans applied parentally were considered the only way to modulate the immune system. However, various investigations in vivo and in vitro have revealed that orally applied beta-glucans also exerted these effects (Stier et al. 2014). One of the main problems with using beta-glucans is its hydrophobic nature due to the large number of -OH groups in their structure (Bai et al. 2014). various methods have been used to solve this problem, replacing the - $\mathrm{OH}$ group by sulfation, phosphorylation, or changing the medium $\mathrm{pH}$ to a very alkaline one. However, these modifications can strongly affect biological activity negatively (Zekovic et al. 2005). The insoluble nature of betaglucans is also a problem when trying to integrate them into the feed. In this study, the methodology used to integrate beta-glucans in pelleted feeds was through a sprinkler, loaded with a fish oil suspension and yeast beta-glucans, which allowed to disperse the glucans evenly on the feed surface, and because of the oil, adhere to feed. An advantage of this procedure is to allow the molecules of the immunostimulants to be exposed directly to shrimp tissue once ingested, thus, accelerating the immunostimulatory effect.

The beta-glucans isolated from different sources have different immunomodulatory properties because of their size and different biochemical properties (Camilli et al. 2018). Differences in their structural characteristics include molecular mass, tertiary structure, polymer loading, conformation, branching degree, and solubility (Zechner-Krpan et al. 2010, Legentill et al. 2015, Yamamoto et al. 2019). Linear beta-glucans formed by 1,3 bonds possesses little or no immunomodulatory activity (Vetvicka \& Vetvickova 2016), while betaglucans possessing 1,3 bonds with ramifications at 1,6 position are the ones with the highest immunogenic activity and known as B-1,3/1,6-glucans (Wang et al 2008, Subramanian \& Philip 2013, Bai et al. 2014). In this study, the results indicated that $C$. glabrata showed the greatest number for $\beta-1,3 / 1,6$ bonds, but it was the yeast with the lowest protective effect against WSSV. Sukumaran et al. (2010) found similar results when working with $P$. monodon finding low survival, so they concluded that a high number of ramifications affected the biological activity as an immunostimulant.

The periodicity and dose to which the beta-glucans are supplied are two important factors determining these molecules' protective effect. An overdose causes immunosuppression that leads to less protection and for animals to succumb to infection (Sajeevan et al. 2009). Thitamadee et al. (2014) found that if beta-glucans were given only once to the black tiger shrimp, the survival effect was $25-50 \%$ compared to the control group, but the second dose of beta-glucans led to a $100 \%$ of mortality. On the other hand, Bai et al. (2010) found that a continuous supply of beta-glucans ceased advantages over the control group while a discontinuous supply was the best option eliminating immune fatigue for $P$. vannamei. In this study, beta-glucans were ministered continuously at a concentration of $0.2 \%$ of the feed thrice a day for 75 days. The WSSV viral particles were introduced orally to shrimp on day 31 , and the mortality rate was $0 \%$ even for the control group not fed with beta-glucans. Therefore, second and third doses of viral particles were provided, finding similar results (days 54 and 66, respectively). These results suggested that the selected shrimp line was WSSV resistant, which was confirmed by providing a fourth dose of viral particles but this time, intramuscularly (day 70). On this occasion, when the primary barrier (exoskeleton) was overcome by direct muscle invasion, mortality for the control group fed without beta-glucans was $60 \%$ during the first $24 \mathrm{~h}$ after viral inoculum, which indicated resistance to WSSV virus by the shrimp line used. It is noteworthy that $40 \%$ of the organisms survived even after $120 \mathrm{~h}$ after the inoculum was injected. Finding shrimp lines resistant to WSSV in Mexico is feasible because of a program initiated by the National Association of Shrimp Larvae Producers (NPLAC, for its acronym in Spanish) and by some independent aquaculture producers in 2013 who introduced shrimp lines resistant to WSSV that have been used by aquaculture in an attempt to counteract WSSV mortalities (Perez-Enriquez et al. 2018).

Regarding the protective effect of beta-glucans, they were applied continuously for 75 days, and some of the assayed beta-glucans caused the immune fatigue observed by Sajeevan et al. (2009) and Fonseca et al. (2013), causing rate mortality even greater than that 
observed for the shrimp not fed with the viral particles. However, in some cases, the yeast beta-glucans protective effect was maintained, increasing survival of WSSV-resistant $P$. vanname $i$ up to $26.66 \%$ higher than that shown by the shrimp in the positive control group, such was the case for the beta-glucans of $D$. hansenii and $C$. humilis. Sukumaran et al. (2010) reported that $S$. cerevisiae beta-glucans had a minimal protective effect (4\%) than the marine yeast beta-glucans in studies with $P$. monodon. In this study, the results indicated that $S$. cerevisiae beta-glucans also provided a good protective effect to shrimp up to $17 \%$ more than the control group. On the other hand, glucans from the marine yeasts $C$. humilis, C. glabrata, P. kudriavzevii, D. hansenii, and terrestrial yeast $S$. cerevisiae showed a significantly higher $(P<0.05)$ value for THC than the negative control group, indicating no presence of immunogenic fatigue. These results also indicated that not all yeast beta-glucans prolongedly exposed to shrimp caused immunogenic fatigue, even with daily exposures up to 73 days.

The results in this study suggest that the immense variety of glucans offer a wide range of possibilities for application as protective molecules that help organisms survive from pathogen attacks.

\section{CONCLUSION}

The results in this study suggest that the beta-glucans obtained from some marine yeasts that coinhabit the Penaeus vannamei culture ponds have a greater protective effect on white shrimp in the presence of WSSV viral particles compared to those of the terrestrial yeast Saccharomyces cerevisiae. Betaglucans obtained from different yeasts have different protective effects; moreover, not all marine yeasts betaglucans have such a protective effect. In some cases, immune fatigue is shown when beta-glucans are administered continuously, but some beta-glucans do not show this immune fatigue and could be safely used, incrementing the surveillance rate for shrimp. Further studies with a tendency to improve shrimp genetic lines are needed to make organisms more resistant to pathogens and diseases. Jointly, resistant shrimp lines and beta-glucans can avoid antibiotics, providing more robust organisms with high survival rates when attacked by pathogens.

\section{ACKNOWLEDGMENTS}

This project is part of the Doctoral studies of Norma Ochoa, funded by CONACYT scholarship number 84042 and CIBNOR projects awarded to Francisco
Magallón. The authors thank Marte Virgen for his support in biomass production; Juan Carlos Rubalcaba for his support in food preparation; Ricardo Sánchez and Cuauhtémoc Ibarra for their support and advice in the performance of the white spot challenge bioassays in the quarantine area of the Instituto Tecnológico de Sonora, and Diana Fischer for English editorial services.

\section{REFERENCES}

Ahmad, A., Anjum, F.M., Zahoor, T., Nawaz, H. \& Ahmed, Z. 2010. Extraction and characterization of $\beta$ d-glucan from oat for industrial utilization. International Journal of Biological Macromolecules, 46: 304-309. doi: 10.1016/j.ijbiomac.2010.01.002

Angulo, M., Reyes-Becerril, M., Tovar-Ramírez, D., Ascencio, F. \& Angulo, C. 2018. Debaryomyces hansenii CBS $8339 \quad \beta$-glucan enhances immune responses and down-stream gene signaling pathways in goat peripheral blood leukocytes. Developmental and Comparative Immunology, 88: 173-182

Bai, N., Gu, M., Wenbing, Z., Xu, W. \& Mai, K. 2014. Effects of $\beta$-glucan derivatives on the immunity of white shrimp Litopenaeus vannamei and its resistance against white spot syndrome virus infection. Aquaculture, 426-427: 66-73.

Bai, N., Zhang, W., Mai, K., Wang, X., Xu, W. \& Ma, H. 2010. Effects of discontinuous administration of $\beta$ glucan and glycyrrhizin on the growth and immunity of white shrimp Litopenaeus vannamei. Aquaculture, 306: 218-224. doi: 10.1016/j. aquaculture.2010.06.017

Camilli, G., Tabouret, G. \& Quintin, J. 2018. The complexity of fungal $\beta$-glucan in health and disease: effects on the mononuclear phagocyte system, Frontiers in Immunology, 9: 673. doi: 10.3389/fimmu. 2018.00673

Castillo-Juárez, H., Campos-Montes, G., CaballeroZamora, A. \& Montaldo, H. 2015. Genetic improvement of Pacific white shrimp (Penaeus (Litopenaeus) vannamei): perspectives for genomic selection. Frontiers in Genetics. doi: 10.3389/fgene.2015.00093

Dalmo, R.A. \& Bogwald, J. 2008. Glucans as conductors of immune symphonies. Fish and Shellfish Immunology, 25: 384-396 doi: 10.1016/j.fsi.2008.04.008

Deng, D., Mei, C., Mai, K., Tan, B.-P., Ai, Q. \& Ma, H. 2013, Effects of a yeast-based additive on growth and immune responses of white shrimp, Litopenaeus vannamei (Boone, 1931), and aquaculture environment. Aquaculture Research, 44: 1348-1357.

Flegel, T.W. 2019. A future vision for disease control in shrimp aquaculture. Journal of the World Aquaculture Society, 50: 249-266. doi: 10.1111/jwas. 12589 
Flores-Miranda, M.C., Luna-González, A., CampaCórdova, A.I., González-Ocampo, H.A., FierroCoronado, J.A. \& Partida-Arangure, B.O. 2011. Microbial immunostimulants reduce mortality in white leg shrimp (Litopenaeus vannamei) challenged with Vibrio sinaloensis strains. Aquaculture, 320: 51-55.

Fonseca-Moreno, E., Gonzales-salas, R. \& Rico-Gutiérrez, R. 2013. Sistema inmune de los camarones. Revista AquaTIC, 38: 68-84.

Gong, H., Jiang, D., Alig, F. \& Lawrence A.L. 2012. Effects of dietary protein level and source on the growth and survival of two genetic lines of specificpathogen-free Pacific white shrimp, Penaeus vannamei. Aquaculture, 29: 118-123.

Jin, M., Xiong, J., Zhou, Q.-C., Yuan, Y., Wang, X.-X. \& Sun, P. 2018. Dietary yeast hydrolysate and brewer's yeast supplementation could enhance growth performance, innate immunity capacity and ammonia nitrogen stress resistance ability of Pacific white shrimp (Litopenaeus vannamei). Fish and Shellfish Immunology, 82: 121-129. doi: 10.1016/j.fsi.2018. 08.020

Kurtzman, C.P. \& Robnett, C.J. 1998. Identification and phylogeny of ascomycetous yeasts from analysis of nuclear large subunit (26S) ribosomal DNA partial sequences. Antonie van Leeuwenhoek, 73: 331-371. doi: 10.1023/A:1001761008817

Legentill, L., Paris, F., Ballet, C., Trouvelot, S., Daire, X., Vetvicka, V. \& Ferrieres, V. 2015. Molecular interactions of $\mathrm{B}(1,3)$ glucans with their receptors. Molecules, 20: 9745-9766. doi: 10.3390/molecules2006 9745

Mohan, K., Ravichandran, S., Muralisankar, T., Uthayakumar, V., Chandirasekar, R., Seedevi, P. \& Rajan, D.K. 2018. Potential uses of fungal polysaccharides as immunostimulants in fish and shrimp aquaculture: a review. Aquaculture, 500: 250-263. doi: 10.1016/j.aquaculture.2018. 10.023

Nitschke, J., Modick, H., Busch, E., von Rekowski, R.W., Altenbach, H.J. \& Mölleken, H. 2011. A new colorimetric method to quantify $\beta$-1,3-1,6-glucans in comparison with total $\beta$-1,3-glucans in edible mushrooms. Food Chemistry, 127: 791-796. doi: 10.1016/ j.foodchem.2010.12.149

Parrilla-Taylor, D.P. 2018. Caracterización genómica del virus del síndrome de la mancha blanca (WSSV) en camaron blanco del Pacífico (Litopenaeus vannamei) del noroeste de México. Tesis Doctoral, Centro de Investigaciones Biológicas del Noroeste, La Paz, 99 pp.

Perez-Enriquez, R., Millán-Márquez, A.M., CruzHernández, P. \& Saucedo-Barrón, C.J. 2018. Population genetics of whiteleg shrimp Litopenaeus vannamei in Sinaloa, Mexico. Revista Mexicana de Biodiversidad, 89: 290-297. doi: 10.22201/ib.2007 8706e.2018.1.2070

Sajeevan, T.P., Philip, R. \& Bright-Singh, I.S. 2009. Dose/frequency: a critical factor in the administration of glucan as immunostimulant to Indian white shrimp Fenneropenaeus indicus. Aquaculture, 287: 248-252.

Sarlin, P.J. \& Philip, R. 2011. Efficacy of marine yeasts and baker's yeast as immunostimulants in Fenneropenaeus indicus: a comparative study. Aquaculture, 321: 173-178.

Shurson, G.C. 2017. Yeast and yeast derivatives in feed additives and ingredients: sources, characteristics, animal responses, and quantification methods. Animal Feed Science and Technology, 235: 60-76. doi: 10.1016/j.anifeedsci.2017.11.010

Sivamaruthi, B.S., Sirilun, S. \& Kesika, P. 2016. Extraction of $\beta$-glucan from Saccharomyces cerevisiae: comparison of different extraction methods and in vivo assessment of immunomodulatory effect in mice. Food Science and Technology, 37: 124-130. doi: 10.1590/ 1678-457X.10716

Stier, H., Ebbeskotte, V. \& Gruenwald, J. 2014. Immunemodulatory effects of dietary yeast beta-1,3/1,6-Dglucan. Nutrition Journal, 13: 38. doi: 10.1186/14752891-13-38

Subramanian, S. \& Philip, R. 2013. Identification of haematological markers in shrimp health assessment from the immune profile of Fenneropenaeus indicus on $\beta-1,3$ glucans administration and white spot syndrome virus challenge. Aquaculture International, 21: 1169-1184.

Sukumaran, V., Douglas, W.L., Sajeevan, T.P. \& Philip, R. 2010. Marine yeast glucans confer better protection than that of baker's yeast in Penaeus monodon against white spot syndrome virus infection. Aquaculture Research, 41: 1799-1805.

Thitamadee, S., Srisala, J., Taengchaiyaphum, S. \& Sritunyalucksana, K. 2014. Double-dose b-glucan treatment in WSSV-challenged shrimp reduces viral replication but causes mortality possibly due to excessive ROS production. Fish and Shellfish Immunology, 40: 478-484.

Uriza-Pinzón, J.P. 2014. Evaluación de la inclusión de los beta- glucanos de Ganoderma lucidum en yogur. Tesis de Magister, Universidad Nacional de Colombia, Bogotá, 82 pp.

Vetvicka, V. \& Vetvickova, J. 2016. Comparison of immunological effects of commercially available $\beta$ glucans: part III. International Clinical Pathology Journal, 2: 78-83. doi: 10.15406/icpj1.2016.02.00046

Volman, J.J., Ramakers, J.D. \& Plat, J. 2007. Dietary modulation of immune function by $\beta$-glucans. 
Physiology and Behavior, 94: 276-284. doi: 10.1016/ j.physbeh.2007.11.045

Wang, Y.C., Chang, P.S. \& Chen, H.Y. 2008. Differential time-series expression of immune-related genes of Pacific white shrimp Litopenaeus vannamei in response to dietary inclusion of beta-1,3-glucan. Fish and Shellfish Immunology, 24: 113-121.

Wang, W., Jing, S., Cenjie, L. \& Zhuang, X. 2016. Application of immunostimulants in aquaculture: current knowledge and future perspectives. Aquaculture Research, 48: 1-23. doi: 10.1111/are.13161

Wilson, W., Lowman, D., Swapna, P.A., Puthumana, J., Bright-Singh, I.S. \& Philip, R., 2015. Immune gene expression profile of Penaeus monodon in response to marine yeast glucan application and white spot syndrome virus challenge. Fish and Shellfish Immunology, 43: 346-356.

Williams, D.L., McNamee, R.B., Jones, E.L., Pretus, H.A., Ensley, H.E., Browder, I.W. \& Di Luzio, N.R. 1991. A method for the solubilization of a1,3-b-Dglucan isolated from Saccharomyces cerevisiae. Carbohydrate Research, 219: 203-213.

Received: 3 March 2020; Accepted: 6 August 2020
Witteveldt, J., Vlak, J.M. \& Van Hulten, M.C. 2004. Protection of Penaeus monodon against white spot syndrome virus using a WSSV subunit vaccine. Fish and Shellfish Immunology, 16: 571-579. doi: 10.1016/ j.fsi.2003.09.006

Yamamoto, F.Y., Castillo, S. \& Gatlin, D.M. 2019. Immunomodulatory effects of $\beta$-glucans derived from Euglena gracilis or Saccharomyces cerevisiae for hybrid striped bass (Morone chrysops $\times$ M. saxatilis). Aquaculture Ressearch, 51: 1211-1221. doi: 10.1111/ are. 14472

Zechner-Krpan, V., Petravić-Tominac, V., Gospodarić, I., Sajli, L., Đaković, S. \& Filipović-Grčić, J. 2010. Characterization of 1,3-glucans isolated from brewer's yeast and dried by different methods. Food Technology and Biotechnology, 48:189-197.

Zekovic, D.B., Kwiatkowski, S., Vrvic, M., Jakovljevic, D. \& Moran, C.A. 2005. Natural and modified (1,3)B-D-glucans in health promotion and disease alleviation. Critical Reviews in Biotechnology, 25: 205-230. 